\title{
Effects of Curing Conditions and Formulations on Residual Monomer Contents and Temperature Increase of a Model UV Gel Nail Formulation
}

\author{
Kentaro Taki, Tomomi Nakamura \\ Department of Chemical Engineering, Kyoto University, Kyoto, Japan. \\ E-mail: taki@cheme.kyoto-u.ac.jp \\ Received August 30 $0^{\text {th }}, 2011$; revised October $5^{\text {th }}, 2011$; accepted October $16^{\text {th }}, 2011$.
}

\begin{abstract}
Recently, the application of ultraviolet (UV) curable monomers to human nails, (also known as UV gel nails) has become a popular decoration technique for women's nails. However, the unreacted layer, the depletion of residual monomers from the cured UV gel nails, which can cause allergy and asthma, and the increase in temperature during curing process, are major concerns. In this study, the thickness of the unreacted layer, the increase in temperature, and the residual contents in cured film of UV gel nail treatment were measured for the first time. The results of this study indicated that the thickness of unreacted layer was not affected by the cast thickness; however, the intensity of UV light and the photoinitiator concentration had significant effect on the thickness of the unreacted layer. To reduce the thickness of the unreacted layer, the intensity of the UV light and the photoinitiator concentration should be increased. However, the maximum temperature observed during the curing of UV gel nails increases with an increase in the intensity of the UV light and the photoinitiator concentration. A suitable cast thickness range (21-150 $\mu \mathrm{m})$, which resulted in the formation of a cured film and without producing temperatures that exceed that of the human body, was identified. The mass fraction of the residuals in the cured layer decreased with an increase in the exposure time, the UV intensity, and the photoinitiator concentration.
\end{abstract}

Keywords: Diffusion, Films, Heat Transfer, Polymers, UV Cure, Gel Nail, Artificial Nail

\section{Introduction}

Recently, ultraviolet (UV) curable monomers (also known as UV gel nails) have become a popular decoration technique for women's nails. Curing (polymerizing) UV gel nails results in the formation of a harder, glossier, more attractive, and durable solid polymer layer than conventional manicures. Although the UV gel nail market is flourishing and has expanded rapidly, safety guidelines on UV gel nail treatment have not yet been established. Clinical studies on UV gel nails have revealed that technicians at nail salons are at risk of developing allergies [1-3] and asthma [4,5] due to UV gel nails. Some UV-curable monomers may cause human skin allergies and asthma in respiratory organs. Most clinical studies have focused on the relationship between the monomer and the human body although dental composite resin, which is applied using photopolymerization, has also been studied to determine the residuals of the cured composites [6-10]. The quantity of monomers remaining in the cured UV gel nails has not been determined yet. To determine the risk the monomers pose to UV gel nail technicians and salon customers, the amount of residuals (monomer, photoinitiator and stabilizer) that leak from cured UV gel nails must be evaluated. Currently, UV gel nail kits are sold in commodity stores. People who are not knowledgeable of the risk that monomers and UV light pose can buy the kit and apply the nails by themselves, which increases the severity of the situation.

The UV gel nail treatment procedure can be divided into several steps: 1) filing the human nail; 2) applying the UV gel nail onto the human nail; 3) exposing the UV gel nail to UV light to polymerize the UV curable monomers; and 4) wiping the unreacted monomers from the cured UV gel nail with a tissue.

UV curable monomers, which are the raw materials used in UV gel nails, have been used in industrial coating processes; they require high intensity UV light and inert 
(nitrogen or carbon dioxide) atmospheres [11]. However, for UV gel nails, the intensity of UV light should be lower (approximately $3-10 \mathrm{~mW} / \mathrm{cm}^{2}$ ), than that used for the industrial processes to avoid unexpected heating. Moreover, inert atmospheres, which can cause asphyxia, cannot be used in UV gel nail salons. Thus, most UV gel nails are cured in air. When a UV-curable monomer is cured in air in the presence of low-intensity UV light, the UV-curable monomers do not achieve $100 \%$ conversion (molecular base) due to oxygen-induced inhibition of polymerization. Thus, an unreacted layer forms on the surface of the cured film and residual monomers exist in the cured film, which must be removed by wiping the surface with a tissue that has been moistened with ethanol. Residual monomers can travel from the cured resin and may cause problems in the human body as has been indicated by clinical studies.

In addition to the residual monomer contents, temperatures observed during the UV curing of monomers should be maintained within the range of human body temperature. UV gel nails use radical polymerizations, which are exothermic chemical reactions. The UV curing reaction is rapid enough (one minute) that heat does not dissipate from the nail, which increases the temperature of the human nail. A rapid temperature increase may occur when the intensity of UV light is too high or the gel nail is too thick. Although the temperature is not a crucial parameter for industrial processes, temperature changes during polymerization should be considered for human nails.

In the present study, the thickness of the unreacted layer, the temperature increase, and the residual content of a model UV gel nail formulation were measured. The thickness of the unreacted layer and the residual contents were quantitatively determined using the gravimetric method and chromatography. The temperature profile and the maximum temperature of the UV curing process were recorded under UV exposure of the UV gel nail. Finally, practical ranges of cast thickness for the UV gel nail, UV light intensities, and exposure times were identified.

\section{Materials and Methods}

\subsection{Materials}

Diurethane dimethacrylate $(436909,225 \mathrm{ppm} \pm 25 \mathrm{ppm}$ topanol as inhibitor, Aldrich, St. Louis, MO), 1-hydroxycyclohexyl phenyl ketone (Irgacure 184, BASF, Ludwigshafen, Germany), and diethyl amine (Wako Pure Chemical Industries, Osaka, Japan) were used as the UV curable monomer, the photoinitiator and the stabilizer, respectively. Diurethane dimethacrylate is a popular ma- terial for UV gel nails and can be used alone or as a mixture with reactive diluents. The monomer, photoinitiator, and stabilizer were mixed in a $50 \mathrm{ml}$ light-shielded polypropylene bottle with a mechanical agitator for 30 min at room temperature and were stored at $40^{\circ} \mathrm{C}$ overnight. Sample solutions containing $1 \%$ or $5 \%$ of the photoinitiator were prepared, and $0.2 \%$ of diethylamine was added to the solutions. The photoinitiator was completely dissolved in the monomer.

\subsection{UV Curing and Extraction}

Using a frame applicator (Imoto Machinery, Kyoto, Japan) operated at $30 \mathrm{~cm} / \mathrm{min}$, the sample solution was applied to a polyester substrate (100 $\mu \mathrm{m}$ in thick, OHP$10 \mathrm{CN}$, OHP sheet, Tochiman, Japan), which was used as an alternative to human nails. The cast film was cut into $3 \mathrm{~cm} \times 3 \mathrm{~cm}$ pieces and was weighed using an electronic balance (minimum readout $=0.01 \mathrm{mg}$, Shimadzu, Kyoto, Japan). Without the polyester substrate, the typical mass of a cast film with a thickness of $100 \mu \mathrm{m}$ was approximately $100 \mathrm{mg}$. The cast thickness of the sample, $L_{0}$, was calculated according to the following equation:

$$
L_{0}=\frac{m_{0}}{\rho A}
$$

where $m_{0}$ is the mass of the cast sample without the polyester substrate, $\rho$ is the density of the sample solution and $A$ is the cast area. The density of the sample solution $\left(1.1 \mathrm{~g} / \mathrm{cm}^{3}\right)$ was obtained from the supplier of the monomer.

Figure 1 shows a schematic diagram of the simultaneous UV exposure and temperature monitoring apparatus. The cast film was placed on a stage, and UV light was guided from a high pressure 200 Watt Mercury Vapor Short Arc lump (OmniCure S2000, ExFo, Quebec, Canada) to the sample stage.

The typical $4 \mathrm{~cm}$ distance between the cast film and the UV light could be adjusted to change the intensity of the UV light. The intensity of the UV light at the center of the film was set to the maximum and was attenuated concentrically. The cast film was exposed to UV light in an atmosphere of air at the desired intensity, $3 \mathrm{~mW} / \mathrm{cm}^{2}$.

Prior to UV exposure, the intensity of the UV light at the center of the film was monitored using a UV meter (Ushio Unimeter UIT-150, Ushio, Japan) and was adjusted to achieve a desired intensity. The intensity of the UV light and the exposure time of the typical curing conditions, which was measured with a commercial UV gel nail lamp, were $3 \mathrm{~mW} / \mathrm{cm}^{2}$ and $60 \mathrm{~s}$, respectively. The intensity of light and the exposure time were varied to investigate their effects on the UV gel nail curing process. The UV exposure experiments were repeated three 
UV light

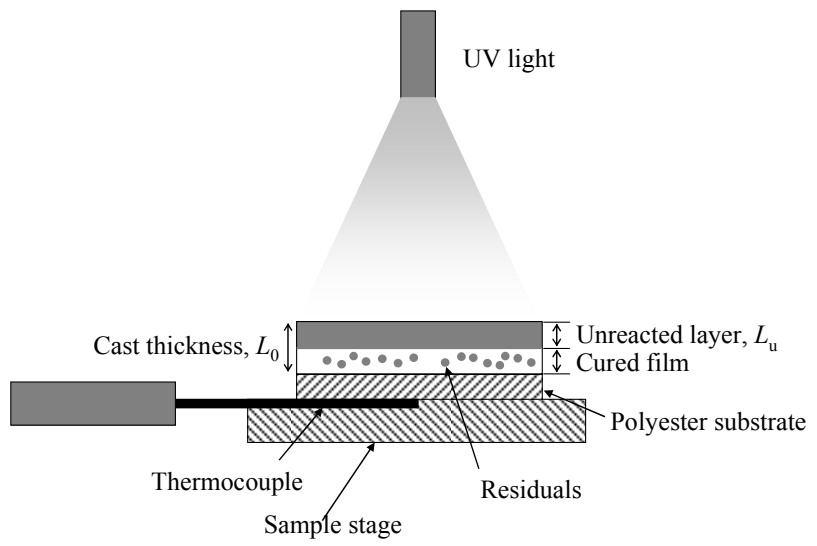

Figure 1. Schematic diagram of the simultaneous UV exposure and temperature monitoring apparatus. The sample solution was cast on a polyester substrate on a sample stage, and the solution was exposed to UV light. A cured film, an unreacted layer and some residual monomer were formed. The temperature increase was monitored using a thermocouple. The figure is not drawn to scale.

times at each condition to assess the reproducibility.

After UV exposure, a tacky unreacted layer usually formed on the cured film. The unreacted layer was removed by wiping with tissue (KimWipes, KimberlyClark, USA) that had been moistened with ethanol (purity $=99 \%$, Wako Pure Chemicals Industries, Osaka, Japan) to remove unreacted monomers on the surface of the cured film. The wiping was performed by hand and was repeated at least three times. After wiping, films were no longer tacky.

This procedure is commonly performed in UV gel nail salons. We used this procedure to determine the amount of residual monomer in the cured layer that could not be removed by wiping. The thickness of the unreacted layer, $L_{u}$, was calculated according to the following equation:

$$
L_{u}=\frac{m_{0}-m_{w}}{\rho A}
$$

where $m_{w}$ is the mass of the wiped film.

The wiped film was placed in a beaker filled with 20 $\mathrm{ml}$ of ethanol and was sonicated for 30 minutes at room temperature to extract the residual monomers, the photoinitiator and the stabilizer from the cured film. Subsequently, the film was dried in an oven at $90^{\circ} \mathrm{C}$ for 1 hour and was cooled to room temperature. The mass fraction of the extracted residuals, $f_{e}$, was calculated according to the following equation:

$$
f_{e}=\frac{m_{w}-m_{e}}{m_{w}}
$$

where $m_{e}$ is the mass of extracted film.

\subsection{GPC Analysis}

Gel permeation chromatography (GPC) was used to determine the amount of monomer in the post-sonication ethanol solution. In total, $10 \mu \mathrm{L}$ of the extracted solution containing the extracted residuals was injected into a GPC. A series of Shodex K806L and K-800D (Showa Denko, Tokyo, Japan) columns were heated to $40^{\circ} \mathrm{C}$. High-pressure liquid chromatography-grade chloroform (Wako Pure Chemicals Industries, Osaka, Japan) was used as the eluent, and a UV-Vis spectrometer $(254 \mathrm{~nm}$, Shimadzu, Kyoto, Japan) was used as the detector.

\subsection{Temperature Increase}

To evaluate the temperature increase during the UV curing process, a K-type thermocouple $(0.5 \mathrm{~mm}$ in diameter $)$ was placed below the polyester film as shown in Figure 1. The heat of photopolymerization during the UV curing reaction caused the temperature of the sample to increase and caused the heat to conduct through the polyester film. The temperature of the film was recorded every $0.167 \mathrm{~s}$.

\section{Results and Discussion}

\subsection{Temperature Increase}

Figure 2 shows the temperature profile of the UV curing reaction. The photoinitiator concentration, the light intensity, the film thickness and the curing time were $1 \%, 3$ $\mathrm{mW} / \mathrm{cm}^{2}, 100 \mu \mathrm{m}$ and $60 \mathrm{~s}$, respectively. When UV light was applied to the film, the temperature increased dramatically from $23.2^{\circ} \mathrm{C}$ to $29.2^{\circ} \mathrm{C}$.

After the maximum temperature was observed, the temperature decreased over time. When the UV light was turned off, the temperature continued to decreases and approached room temperature asymptotically. Two temperature ranges were observed during the UV-curing reaction. The first temperature range was associated with the heat of photopolymerization and the absorbance of UV light by the sample. The second temperature range was attributed to the heat of polymerization. Using the maximum temperature, a temperature index of the profile was obtained and was employed thereafter.

\subsection{GPC Analysis}

To determine the amount of residuals in the cured film, the wiped film was sonicated in ethanol. Residuals were extracted into ethanol, and the solution was injected onto the GPC column to analyze the residual monomer contents.

Figure 3 shows the GPC profile of the extracted solution and the monomer. The monomer peak was observed at $12.4 \mathrm{~min}$, and the extracted solution showed two distinct peaks. The earliest peak of the chromatograph of the 


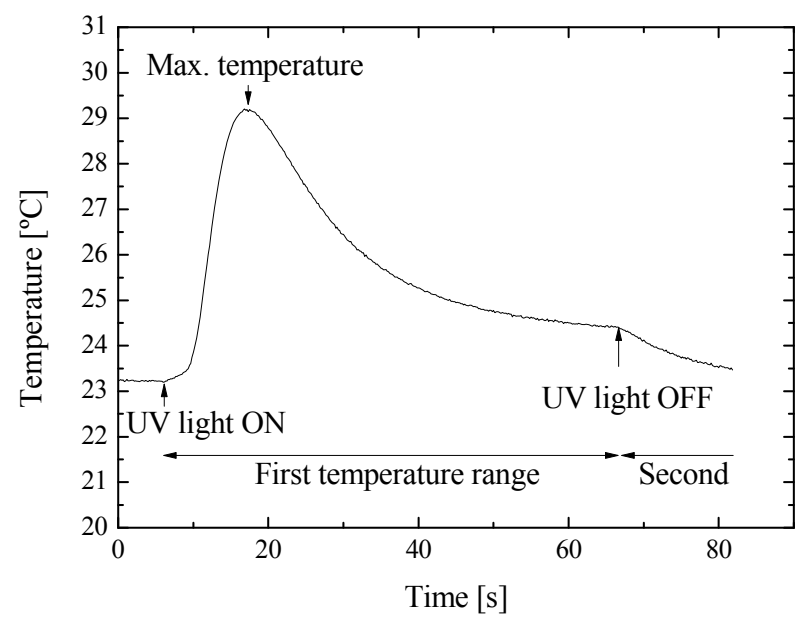

Figure 2. Temperature profile of the UV curing reaction. Intensity of the UV light, thickness of the cast film and exposure time were $3 \mathrm{~mW} / \mathrm{cm}^{2}, 100 \mu \mathrm{m}$ and $60 \mathrm{~s}$, respectively. The maximum temperature was achieved after UV light was on and then the temperature gradually decreased over time. The temperature decrease became more rapid after the UV light was turned off.

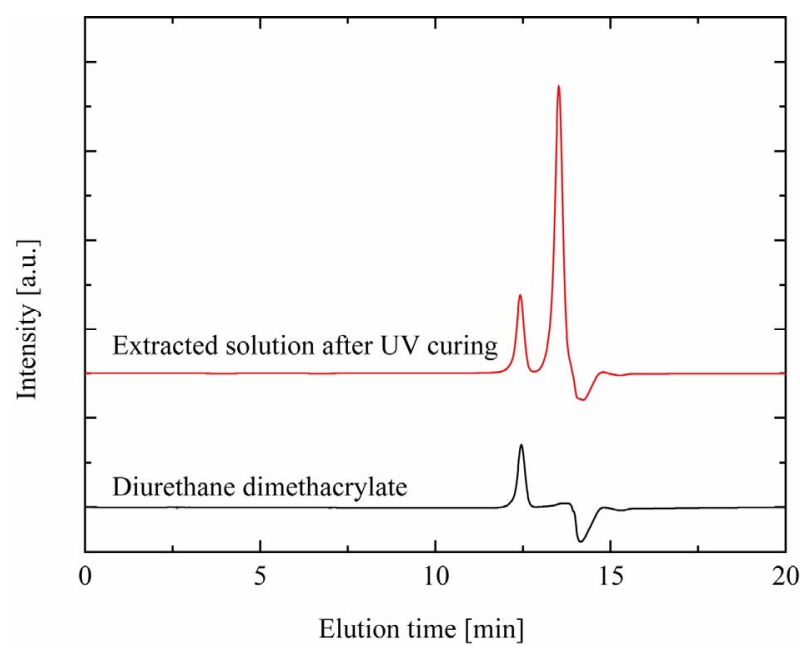

Figure 3. GPC profile of the monomer and the extracted solution from the cured sample. The "Diurethane dimethacrylate" curve was obtained by dissolving the diurethane diacrylate monomer in ethanol. The "Extracted solution after UV curing" was prepared by sonificating the wiped film in ethanol.

extracted solution was observed at $12.4 \mathrm{~min}$ and was attributed to the monomer; thus, unreacted monomer existed in the cured film and was not removed by wiping the surface of the film by hand. This result implies that the UV gel nails contained some amount of residuals in the cured gel nail after treatment.

The photopolymerization rate depends on the diffusivity of the monomer, which decreases with an increase in the degree of polymerization. When the rate of monomer diffusion is slow, the monomer cannot react with the radicals [12]. Therefore, the degree of photopolymerization does not reach $100 \%$ and the residual monomers were obtained. Based on the height of the peak at 12.4 min and the calibration curve, the mass fraction of monomer in the cured film was $90 \%$.

The right-most peak was attributed to a mixture of the photoinitiator and the stabilizer, which absorbs light at $254 \mathrm{~nm}$.

\subsection{Effect of the Cast Thickness}

To determine a suitable cast thickness for the following investigations, the effect of the cast thickness on the thickness of the unreacted layer and the maximum temperature was investigated.

Figure 4 shows the effect of the cast thickness, $L_{0}$, on the thickness of unreacted layer, $L_{u}$. The photoinitiator concentration and the UV light intensity were set to $1 \%$ and $3 \mathrm{~mW} / \mathrm{cm}^{2}$, respectively. When the cast thicknesses was equal to $50 \mu \mathrm{m}$ or $200 \mu \mathrm{m}$, the thickness of the unreacted layer was 21 and $22 \mu \mathrm{m}$, respectively. The coefficient of variance $(\mathrm{CV})$ of the thickness of the unreacted layer was $3 \%$, which was comparable to the repeated error. The results indicated that the cast thickness did not affect the thickness of the unreacted layer. Based on the thickness of unreacted layer, the monomers cannot be cured when the cast thickness is less than $21 \mu \mathrm{m}$. The formation of an unreacted layer was observed because oxygen in the air diffused to the cast film and inhibited the polymerization reaction by reacting with radicals [13-15].

Figure 5 shows the effect of the cast thickness on the maximum temperatures. The formulation and curing conditions were identical to those shown in Figure 4. When the cast thickness was set to $50 \mu \mathrm{m}$, the maximum temperature was $25.2^{\circ} \mathrm{C}$, which is close to room temperature. Alternatively, when the cast thickness was 200 $\mu \mathrm{m}$, the maximum temperature was $40.9^{\circ} \mathrm{C}$, which is warmer than the human body temperature. The maximum temperature of the cast film with a thickness of 150 $\mu \mathrm{m}$ was less than body normal temperature.

Based on the findings of the present study, when the cast thickness is $100 \mu \mathrm{m}$ the thickness of the unreacted layer is $21 \mu \mathrm{m}$, and the maximum temperature is $26.8^{\circ} \mathrm{C}$. A cast thickness of $100 \mu \mathrm{m}$ is a suitable cast thickness that allows the monomers to be cured without exceeding the human body temperature. Thus, based on this investigation, a cast thickness of $100 \mu \mathrm{m}$ was employed.

\subsection{Effect of Exposure Time}

Figure 6 shows the effect of the exposure time on the 


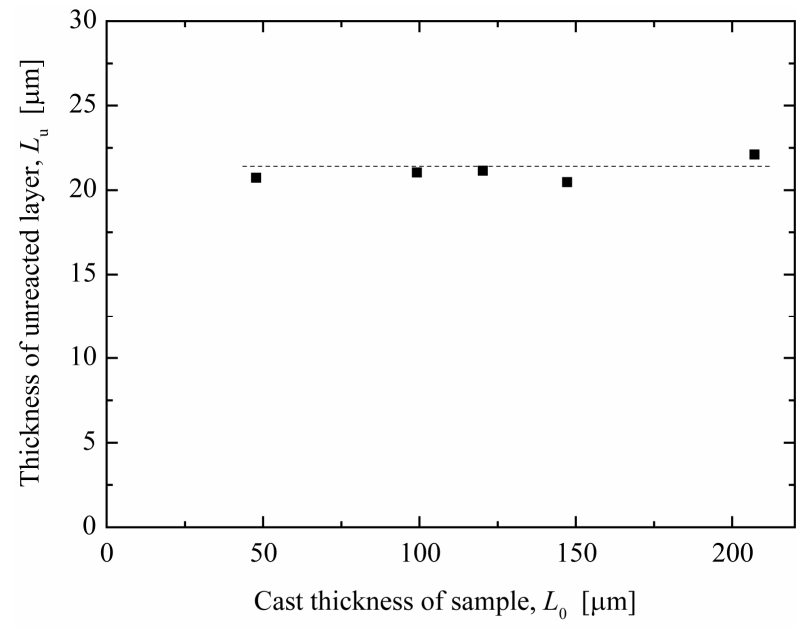

Figure 4. Effect of the cast thickness of the sample on the thickness of the unreacted layer. The photoinitiator concentration was 1\%. Exposure time was $60 \mathrm{~s}$.

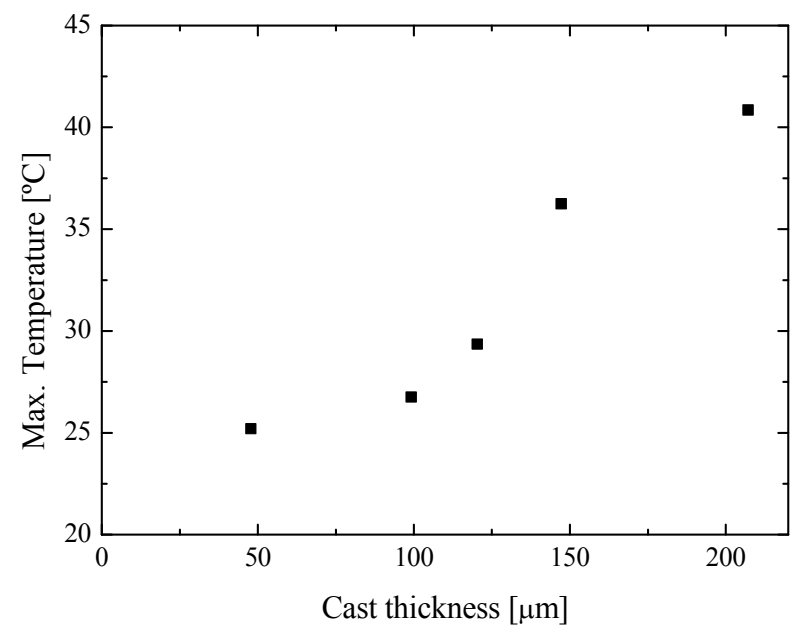

Figure 5. Effect of the cast thickness on the maximum temperatures. The photoinitiator concentration was $1 \%$. The exposure time was $60 \mathrm{~s}$.

thickness of the unreacted layer. As shown in the figure, at $40 \mathrm{~s}$, the thickness of the unreacted layer was $25 \mu \mathrm{m}$. As the exposure time increased to $180 \mathrm{~s}$, the thickness of the unreacted layer gradually decreased to $18 \mu \mathrm{m}$. At exposure times between $180 \mathrm{~s}$ and $500 \mathrm{~s}$, the thickness of the unreacted layer did not change within the deviation of the measurement. These results indicate that the thickness of the unreacted layer can be reduced to certain values by increasing the exposure time. The size of the unreacted layer is determined by the rate of oxygen diffusion and the radical generation, which are competitive phenomena. Oxygen diffusion is not affected by the exposure time, while the radical content is proportional to the exposure time [13-15]. An unreacted layer thickness

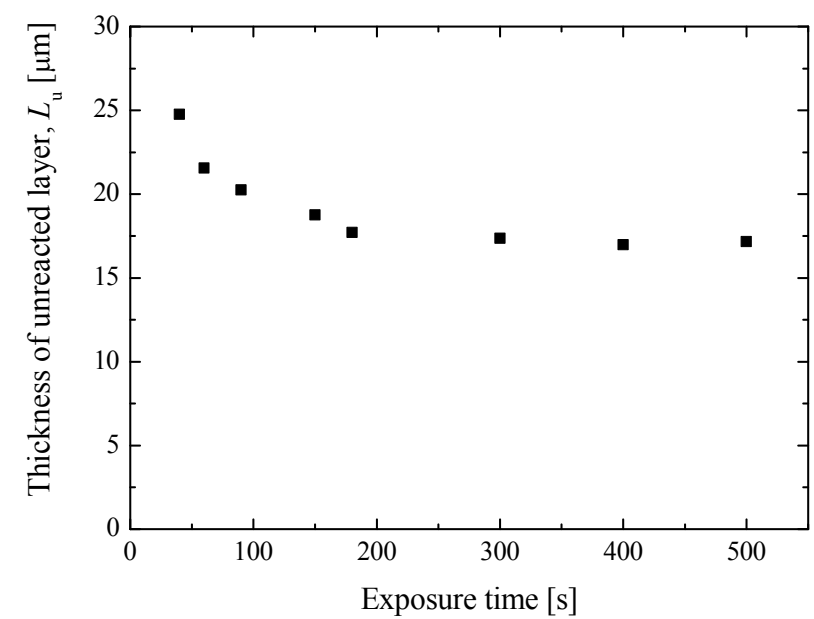

Figure 6. Effect of curing time on the thickness of the unreacted monomer layer. The UV light intensity was $3 \mathrm{~mW} / \mathrm{cm}^{2}$. The photoinitiator concentration was $1 \%$. The cast thickness was $100 \mu \mathrm{m}$.

of $18 \mu \mathrm{m}$ can be attained by balancing the rates of radical generation and oxygen diffusion.

Figure 7 shows the effect of the exposure time on the mass fraction of the residuals. The mass fraction was $32.2 \%$ after $40 \mathrm{~s}$ of exposure and decreased gradually with an increase in the exposure time. The mass fraction was equal to $7.7 \%$ and $5.7 \%$ at curing times of $400 \mathrm{~s}$ and $500 \mathrm{~s}$, respectively. Unlike the thickness of the unreacted layer, the mass fraction did not converge to a specific value. The rate of the diffusion of radicals and monomers decreased with an increase in conversion, which reduces the reaction rate. Thus, the photopolymerization reaction became slow but continued at $500 \mathrm{~s}$.

\subsection{Effect of UV Intensity}

Figure 8 shows the effect of the UV intensity on the thickness of the unreacted layer. The photoinitiator concentration was set to $1 \%$. The thickness of the unreacted layer was equal to $21 \mu \mathrm{m}$ when the intensity of UV light was $3 \mathrm{~mW} / \mathrm{cm}^{2}$, which is the typical intensity of a commercial light. The thickness of the unreacted layer decreased with an increase in the intensity of the UV light.

Figure 9 shows the mass fraction of residuals in the wiped film. At an intensity of $3 \mathrm{~mW} / \mathrm{cm}^{2}, 18 \%$ of the residuals were extracted from the film. The mass fraction of the residuals decreased with an increase in the intensity of UV light. At an intensity of $30 \mathrm{~mW} / \mathrm{cm}^{2}, 3 \%$ of the residuals were extracted from the film, which was $1 / 6$ less than the amount of extracted residuals obtained at an intensity of $3 \mathrm{~mW} / \mathrm{cm}^{2}$. Even though the film was wiped with an ethanol-wetted tissue, the residual monomers remained in the film. 


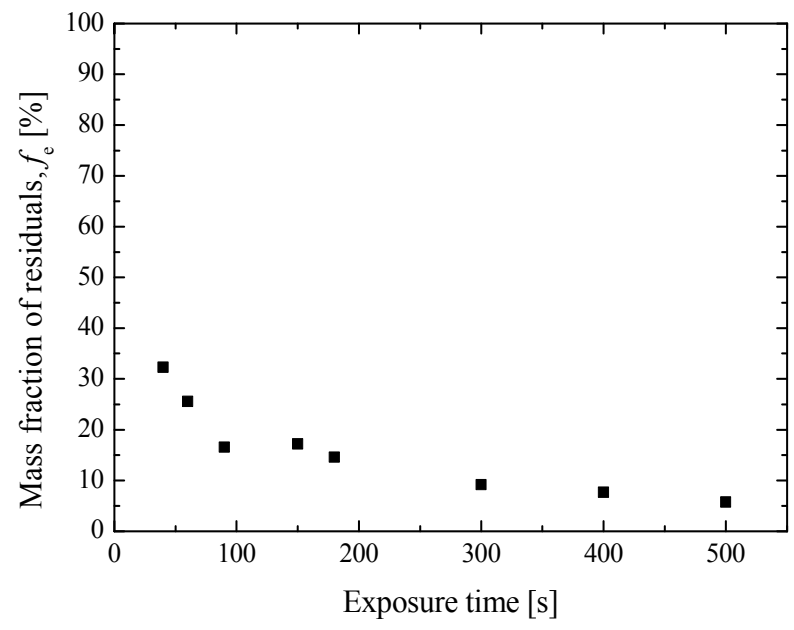

Figure 7. Effect of exposure time on the mass fraction of the residuals. The UV intensity was $3 \mathrm{~mW} / \mathrm{cm}^{2}$. The photoinitiator concentration was $1 \%$. The cast thickness was $100 \mu \mathrm{m}$.

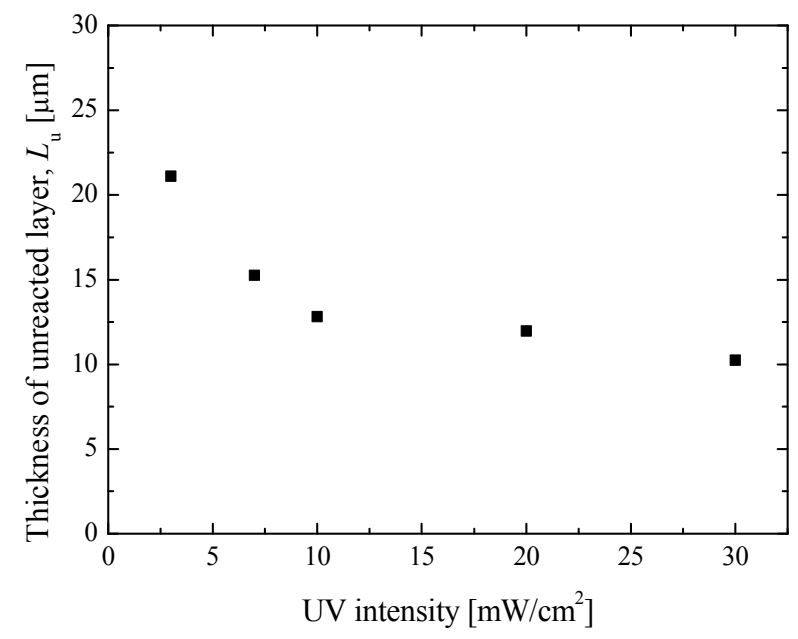

Figure 8. Effect of the UV light intensity on the thickness of the unreacted layer. The photoinitiator concentration was $1 \%$. The cast thickness was $100 \mu \mathrm{m}$.

Figure 10 shows the maximum temperature during the UV-curing process. The maximum temperature increased with an increase in the intensity of UV light. At intensities of 20 and $30 \mathrm{~mW} / \mathrm{cm}^{2}$, the maximum temperature exceeded the human body temperature. Under these conditions, a human may feel warm. Thus, a UV intensity range of 3 to $10 \mathrm{~mW} / \mathrm{cm}^{2}$ is recommended.

\subsection{Effect of the Photoinitiator Concentration}

Figure 11 shows the effect of the photoinitiator concentration on the thickness of the unreacted layer. At a photoinitiator concentration of $5 \%$, the thickness of the unreacted layer was $11 \mu \mathrm{m}$, which was less than that for a photoinitiator concentration of $1 \%(21 \mu \mathrm{m})$. Thus, the

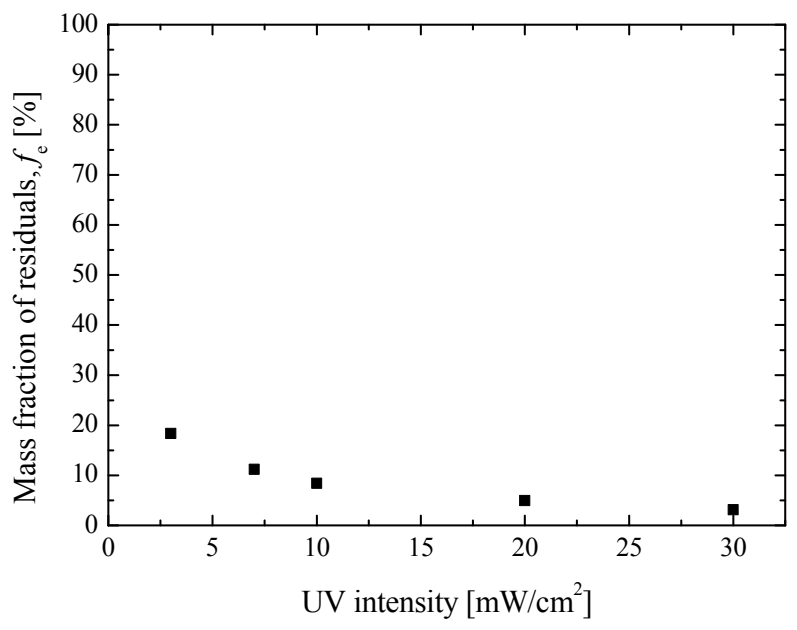

Figure 9. Effect of UV light intensity on the mass fraction of the residuals. The photoinitiator concentration was $1 \%$. The cast thickness was $100 \mu \mathrm{m}$.

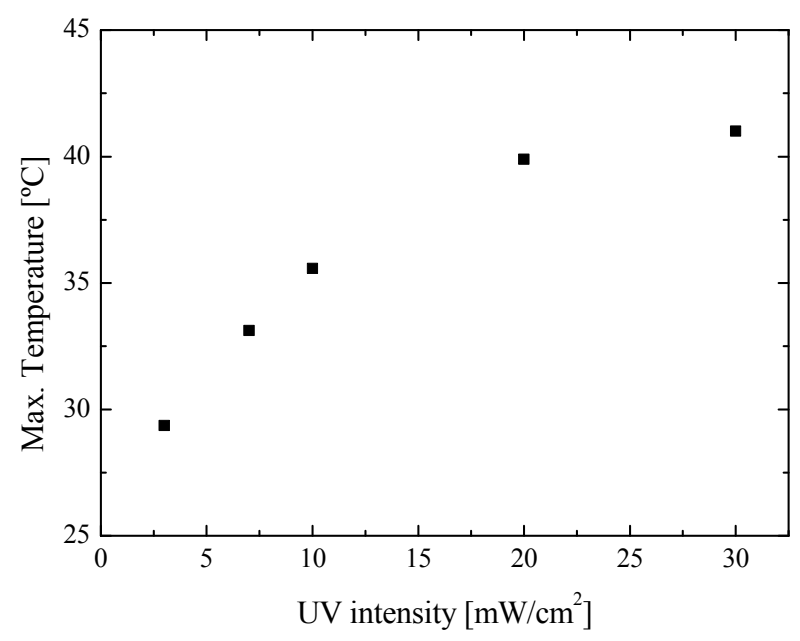

Figure 10. Effect of UV light intensity on the maximum temperature. The photoinitiator concentration was $1 \%$. The cast thickness was $100 \mu \mathrm{m}$.

thickness of the unreacted layer decreased with an increase in the photoinitiator concentration.

The amount of radicals formed in a 5\% solution of the photoinitiator was greater than that observed in a $1 \%$ solution. As the rate of radical generation increased, the balance between oxygen diffusion and radical generation shifted, and thinner unreacted layers were obtained.

Figure 12 shows the effect of the photoinitiator concentration on the maximum temperature. The difference between the maximum temperature associated with a photoinitiator concentration of $5 \%$ and $1 \%$ was greatest at an intensity of $3 \mathrm{~mW} / \mathrm{cm}^{2}$ and decreased with an increase in UV intensity. At an intensity of $12 \mathrm{~mW} / \mathrm{cm}^{2}$, the difference between the maximum temperatures was 


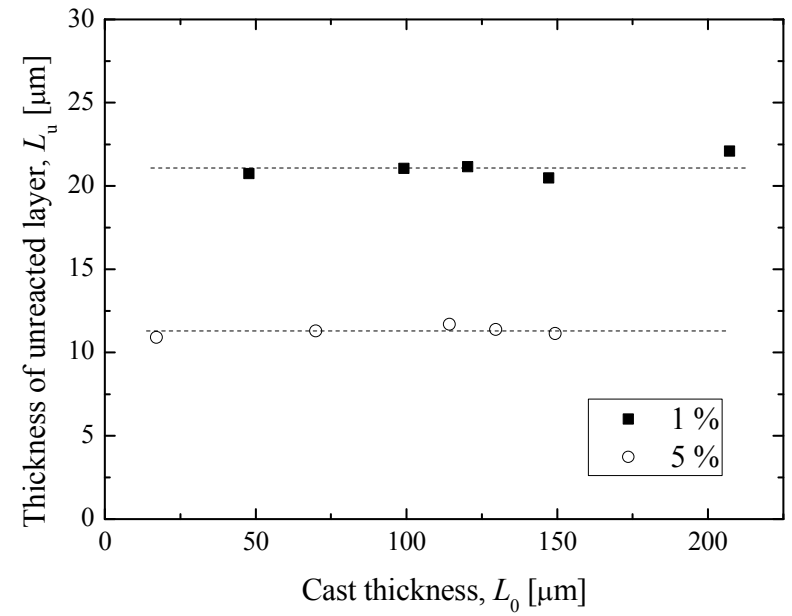

Figure 11. Effect of the photoinitiator concentration on the thickness of the unreacted layer. The UV light intensity was $3 \mathrm{~mW} / \mathrm{cm}^{2}$. The exposure time was $60 \mathrm{~s}$. The cast thickness was $100 \mu \mathrm{m}$.

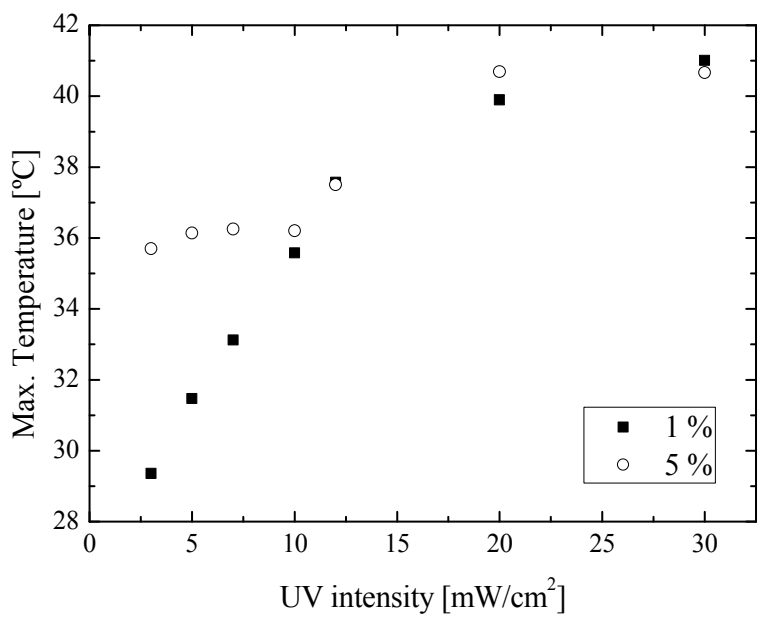

Figure 12. Effect of the photoinitiator concentration on the maximum temperature. Cast thickness was $100 \mu \mathrm{m}$, and exposure time was $60 \mathrm{~s}$.

negligible and remained constant as the intensity of UV light was further increased. Although an increase in the UV intensity increased the maximum temperature, the effect of the photoinitiator concentration was more pronounced for lower UV intensities.

Figure 13 shows the effect of the photoinitiator concentration on the amount of extracted residuals. As shown in the figure, the amount of extracted residuals decreased with an increase in the photoinitiator concentration.

\section{Limitations}

The weight percent of residuals decreased with an increase in the exposure time, intensity of UV light, and

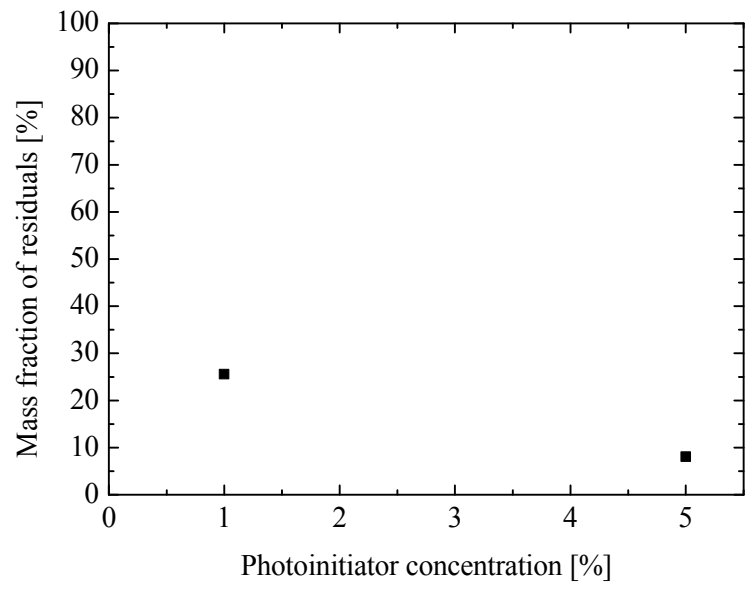

Figure 13. Effect of the photoinitiator concentration on the amount of extracted residuals. UV light intensity was 3 $\mathrm{mW} / \mathrm{cm}^{2}$, exposure time was $60 \mathrm{~s}$ and cast thickness was 100 $\mu \mathrm{m}$.

photoinitiator concentration. However, the weight percent of extracted residuals was greater than the typical specifications of cosmetic materials, which is $10 \mathrm{ppm}$ of residual monomers and photoinitiators. Thus, the amount of residuals must be further decreased for UV gel nail treatment.

\section{Conclusions}

A method to evaluate the thickness of the unreacted layer, the temperature profile of the reaction and the residual monomer content of cured films was developed for UV gel nail treatment. The thickness of the unreacted layer was not affected by the thickness of the cast film; however, the intensity of the UV light and the photoinitiator had an effect on the thickness of the unreacted layer. To reduce the thickness of the unreacted layer, the UV intensity and the photoinitiator concentration can be increased. However, an increase in the photoinitiator concentration or the UV intensity can increase the maximum temperature of the UV gel nail curing process. A suitable range of cast thicknesses $(21-150 \mu \mathrm{m})$, which resulted in the formation of a cured layer and did not increase the temperature beyond that of the human body was identified.

\section{Acknowledgements}

The authors gratefully acknowledge Professor M. Ohshima and Dr. S. Nagamine for their discussion, and Ms. K. Tomohara for introducing us to the field of UV gel nails. This study was partly supported by the New Energy and Industrial Technology Development Organization, Japan (NEDO, 09A16003d) and the Grant-in-Aid for Young Scientists from the Japan Society for the Pro- 
motion of Science (JSPS, 20760513 and 22760587).

\section{REFERENCES}

[1] W. Hemmer, M. Focke, F. Wantke, M. Götz and R. Jarisch, "Allergic Contact Dermatitis to Artificial Fingernails Prepared from UV Light-Cured Acrylates," Journal of the American Academy of Dermatology, Vol. 35, No. 3, Part 1, 1996, pp. 377-380. doi:10.1016/S0190-9622(96)90600-3

[2] P. Rich, "Nail Cosmetics and Camouflaging Techniques," Dermatologic Therapy, Vol. 14, No. 3, 2001, pp. 228-236. doi:10.1046/j.1529-8019.2001.01023.x

[3] L. Constandt, E. V. Hecke, J. M. Naeyaert and A. Goossens, "Screening for Contact Allergy to Artificial Nails," Contact Dermatitis, Vol. 52, No. 2, 2005, pp.73-77. doi:10.1111/j.0105-1873.2005.00496.x

[4] R. Sauni, P. Kauppi, K. Alanko, M.-L. Henriks-Eckerman, M. Tuppurainen and T. Hannu, "Occupational Asthma Caused by Sculptured Nails Containing Methacrylates," American Journal of Industrial Medicine, Vol. 51, No. 12, 2008, pp. 968-974. doi:10.1002/ajim.20633

[5] S. R. Reutman, A. M. Rohs, J. C. Clark, B. C. Johnson, D. L. Sammons, C. A. Toennis, S. A. Robertson, B. A. MacKenzie and J. E. Lockey, "A Pilot Respiratory Health Assessment of Nail Technicians: Symptoms, Lung Function, and Airway Inflammation," American Journal of Industrial Medicine, Vol. 52, No. 11, 2009, pp. 868-875. doi:10.1002/ajim.20751

[6] W. D. Cook, "Photopolymerization Kinetics of Dimethacrylates Using the Camphorquinone Amine Initiator System," Polymer, Vol. 33, No. 3, 1992, pp. 600-609. doi:10.1016/0032-3861(92)90738-I

[7] K. S. Anseth, S. M. Newman and C. N. Bowman, "Polymeric Dental Composites: Properties and Reaction Behavior of Multimethacrylate Dental Restorations," $A d$ vances in Polymer Science, Vol. 122, 1995, pp. 177-277.

[8] A. D. Neves, J. A. C. Discacciati, R. L. Oréfice and M. I.
Yoshida, "Influence of the Power Density on the Kinetics of Photopolymerization and Properties of Dental Composites," Journal of Biomedical Materials Research Part B: Applied Biomaterials, Vol. 72B, No. 2, 2005, pp. 393400. doi:10.1002/jbm.b.30179

[9] C. Sanglar, M. Defay, H. Waton, A. Bonhomme, S. Alamercery, R. Baudot, O. Paisse and M. F. Grenier-Loustalot, "Commercial Dental Composite: Determination of Reaction Advancement and Study of the Migration of Organic Compounds," Polymers and Polymer Composites, Vol. 13, No. 3, 2005, pp. 223-234.

[10] F. F. Silva, L. C. Mendes, M. Ferreira and M. R. Benzi, "Degree of Conversion versus the Depth of Polymerization of an Organically Modified Ceramic Dental Restoration Composite by Fourier Transform Infrared Spectroscopy," Journal of Applied Polymer Science, Vol. 104, No. 1, 2007, pp. 25-30. doi:10.1002/app.23248

[11] R. Schwalm, "UV Coatings: Basic, Recent Developments and New Application," Elsevier, Amsterdam, 2007.

[12] M. D. Goodner, H. R. Lee and C. N. Bowman, "Method for Determining the Kinetic Parameters in Diffusion-Controlled Free-Radical Homopolymerizations," Industrial \& Engineering Chemistry Research, Vol. 36, No. 4, 1997, pp. 1247-1252. doi:10.1021/ie9605387

[13] D. Dendukuri, P. Panda, R. Haghgooie, J. M. Kim, T. A. Hatton and P. S. Doyle, "Modeling of Oxygen-Inhibited Free Radical Photopolymerization in a PDMS Microfluidic Device," Macromolecules, Vol. 41, No. 22, 2008, pp. 8547-8556. doi:10.1021/ma801219w

[14] A. K. O'Brien and C. N. Bowman, "Modeling the Effect of Oxygen on Photopolymerization Kinetics," Macromolecular Theory and Simulations, Vol. 15, No. 2, 2006, pp. 176-182. doi:10.1002/mats.200500056

[15] A. K. O'Brien and C. N. Bowman, "Impact of Oxygen on Photopolymerization Kinetics and Polymer Structure," Macromolecules, Vol. 39, No. 7, 2006, pp. 2501-2506. doi: $10.1021 / \mathrm{ma} 0518631$ 